\title{
Higher Education and Reform of Postgraduate Education in China Compared with that in Tajikstan
}

\author{
Y.S. WANG, Saidshu Bakdalatov \& G.Y. LI \\ College of Electronic Information and Control Engineering, Beijing university of technology, Beijing, 100124
}

\begin{abstract}
Today the higher education system including graduate and postgraduate, has become increasingly important for almost all countries. The situation of higher education in Tajikistan and China was presented, and the most significant aspects were discussed, such as the existing problems, system reform. Furthermore, the education system was analyzed, and then the demonstration was summed up. Finally, proposals were put forward.
\end{abstract}

KEYWORD: Postgraduate education, analyze and reform, existing problems.

\section{INTRODUCTION}

Educational reform started in 1994 with the aim of determining the strategic directions in which the country's higher education should develop. The last draft of the Law on Higher Education and Professional Postgraduate Education was revised in 2009. The key legislative documents are the Law on Education, the Law about Higher Education, Professional Postgraduate Education and the National Concept of Education.

\section{STATUS OF POSTGRADUATE ENROLLMENT IN TAJIKISTAN}

The situation of higher education in Tajikistan has changed radically since independence. The total number of institutions of higher education throughout the country has grown from 13 in 1991 to 30 in 2012. New institutions of higher education and branches of the central ones were opened in the north of the country (Sughd oblast) and in the Gorno Badakhshan Autonomus Oblast. A number of institutions have been established under the auspices of various authorities (various ministries including military ones).Student numbers are increasing every year and the gender balance is improving. The percentage of growth in the number of higher education students was $5.45 \%$ (for the period 2004 - 2008).Students with 'specialist' or 'Master' degrees may be accepted on a competitive basis to postgraduate courses leading to a Candidate of Science diploma (aspirantura), which takes three years. Candidates of Science may be admitted to Doctor of Science (doctorontura) courses which also take a maximum of three years. Recently, the country started the introduction of alternative doctoral programmers, leading to the degree of $\mathrm{Ph} . \mathrm{D}$. Foreign students may be admitted to aspirantura and doctorantura studies in accordance with international and intergovernmental agreements[1].

\section{POSTGRADUATE EDUCATION SYSTEM REFORM IN CHINA AND MEASURES}

In recent years, the reform of higher education in China, rised the attention of education, academic, universities, teachers, students and community. Many colleges and universities began to shorten the academic master's graduate education time, part of the relatively early completion of the academic structure reform of colleges and universities emergence of the 'return' phenomenon. 'Return' phenomenon of the generation, fully demonstrates China's current postgraduates working in the academic structure reform is to continuously explore, to be a sound initial stage. I tried to graduate from our Master's academic background of the reform start to fully understand the Master system reform in China based on the necessity to ensure the quality of the graduates of our master and to meet socio-economic development of the training needs of postgraduates as the starting point and destination, analyses at this stage Master system reform in China. 
The causes of these problems and explore solutions to these problems, promoting the reform of China's postgraduate education system smoothly.

\section{COMPARISON WITH CHINESE POSTGRADUATE SYSTEM}

Since the implementation of reform and opening up, the reform and development of higher education in China have made significant achievements. A higher education system with various forms, which encompasses basically all branches of learning, combines with degree-education, non-degree education, integrates college education, undergraduate education, graduate education, has taken shape. Higher education in China has played an important role in the economic construction, science progress and social development by bringing up large scale of advanced talents and experts for the construction of socialist modernization.

Nowadays Chinese education system and post graduation system have big progress, and become more closely with international standard for graduate and post graduate system, but unfortunately Tajikistan has no such good quality of education like China. Tajikistan post graduate system compare with China, began to improve recently, and China actively help and support Tajikistan in this direction. In fact that in the last year a lot of Tajik students graduated from Chinese Universities and doing his research in their own country. Matter of course, if compare with Chinese government, Tajikistan government has no enough financial supporting post graduate education system. Thank to Chinese government education program for scholarship like Chinese government scholarship, Tajik graduate and post graduate students becoming more and more, and our education system will be closely depend from China education system.

\section{THE PROBLEMS OF MASTER'S SYSTEM PERFORMANCE IN CHINA AND THE REASONS}

\subsection{Unclear Masters's postgraduate training targeting impede the smooth progress of reform.}

Postgraduate training objectives change is a major reason for the reform of education system. In many developed countries, higher education, master's graduate training objectives are located in developing a 'generalist' and 'professional-type people' in the middle stage, a master's degree belongs to the transitional degree, Master's training mode so diversified characteristics, period of the program were generally shorter. Now, with the improve of my college and educate graduate students in all areas of society on a higher level science and technology needs. Research institutes, universities and other academic research units in the object has been recruiting up to doctorate degree level, while the master after graduating from the majority of the enterprises engaged in practical, technical or management of a strong work. In this case, to maintain the original master's 'academic-type people' training objectives remain unchanged. It is obviously not suitable for social development and the demand for high-level personnel. China's higher education institutions should be based on the actual schools, taking full account of differences in different disciplines, based on the correct positioning of postgraduates training objectives, in this context to promote Master system reform work. Do not consider repositioning targeting training objectives or in the case of ambiguity, blindly implement Master academic reforms is bound to trigger a series of contradictions and problems which would hinder the smooth development of reform.

\subsection{Inadequate reform supporting resulted in students' quality of training being called into question}

In developed countries, higher education, master's graduate school system for two years or even shorter, but because of its education system is relatively mature, the quality of training personnel have a high acceptance. In China, some colleges and universities implement the reform of postgraduate education system in a more simple and just way by reducing the hours reduced to two years of academic life, for curriculum, teaching and guidance methods, teaching and academic management, closely related to the policy of reform, there is no supporting for the implementation of effective land reform, the result will inevitably lead to questions for the students to develop the quality. For example, in the basic curriculum unchanged, compressed hours means reducing the amount of knowledge of students in classroom learning; in teacher education and teacher's method, the same circumstances, the reduction in learning time means that students and tutors have fewer communicate opportunities in scientific research practice, the depth of the subject is difficult guarantees.

\subsection{Common analysis of the postgraduate system}

\section{(1)State and social factors}

As a high-level education, postgraduate education responsible for the training of highly qualified personnel and the development of national science and technology. In a way, the quality of graduate education represents a country's level of development of science and technology and productivity. Therefore, graduate education will 
inevitably be affected by the state and society in many ways.

First of all, education degree in the graduate education system has hysteresis. Due to the special historical factors, the graduate education in China started late. In recently, our degree and postgraduate education still lack regulations, legal constraints and protection lawsuits, and appear universities which illustrates this point. States should be regulate and intervention more strong to ensure the steady development of graduate education.

Second, students in postgraduate enrollment system is a guarantee of quality, it is an important factor affecting the quality of graduate education.

Finally, while theoretically we are actively exploring the ways to build efficient graduate quality assurance system, and some schools are actively practicing and exploring of the school graduate quality safeguard system, and adopted a series of effective measures to ensure the quality of graduates. But at present, there is no real system to establish a quality assurance system of graduate education.

\section{(2) The education factor}

In the education process, there are two subjects: one is the students.

First, the students motivation are complicated. In addition, many students do not like undergraduate, or Bachelor's degree in popular professional, employment prospects. Because of existing unsatisfactory work, there are some incumbents expect to get a better job aspects and treatment through graduate school. Even some educated well to others [2].

Second, the quality of the students themselves. Graduate student research interests the quality of work, way of thinking and the cultivation of observation ability, affects the study quality. If a student has no interest in his research it will lead inefficient, lack of responsibility, ultimately have no research results.

Third, neglect the importance of interpersonal communication, Lacking of good communication long time may lead some mental illnesses easily such as depression, which seriously affecting their studies and future development .

\section{(3) The educator factor}

Mentor is the direct organizer of graduate education, instructor of academic level and personality training, who directly influence and restrict the quality of postgraduate training. The mentor has an important influence on the students' education growth, even students' lives. The teacher should play as exemplary in all respects, pay attention to their own behavior model, we should stick to guide students in the right way, inclusive student in a tolerant attitude, rather than guess and suspicion about students. Harmonious relationship between teachers and students can guarantee a pleasant mood, helps improve learning efficiency.
Students will inevitably make mistakes, the teachers should not consider it too complicated. Teachers should give their opportunities to self correct. Students should sustain teachers, strict demands on themselves, and listen to the teacher's teaching. Teachers' ability in scientific research, academic status have a direct impact on the quality of graduate education. Mentors like a beacon in the dark night sky, stands at the forefront of academic and research direction for students, based on his own profound knowledge to guide and enlighten students in some studies.

\section{(4) Training process factor}

Part of the training process is the most direct impact on the quality of graduate education. It includes training factor model, curriculum, and management aspects and other aspects.

\section{MANAGEMENT OF EDUCATION SYSTEM}

Another important issue is the need for a greater degree of autonomy and independence of educational institutions in regard to managing their own problems and finding creative sustainable solutions. At present, almost all operational functions within education are centralized at the governmental level, either at the central or regional level, which in turn has lead to overlapping of functions across different levels, constraining individual educational institutions to take initiative and responsibility upon themselves. There is also a need to ensure closer links between general secondary education, primary, secondary and highest vocational education. There is a need to elaborate in detail norms and rules for granting greater independence to educational institutions, especially in the sphere of financial independence, through adopting laws which would allow raising of additional sources of funding at the local and institutional level [3].

Successful management of the education system most depend on the availability and use of relevant, timely and authentic information. Successful implementation of management functions is impossible without an advanced and efficiently functioning management information system. Under the education sector assessment, information base of the education system in Tajikistan and China is extremely weak, and the Ministry of Education's capability in education information management needs substantial investment.

\section{CONCLUSION}

This article introduces the present situation of graduate education, and comparison with other aspects of postgraduate education, sums up the 
quality of postgraduate education in Tajikistan which showed many problems, such as resource shortages, teaching mode, finance shortages and management problems, also there was emphasized a lot of other question and gave comparisons between Chinese and Tajik post graduate education, these education problems and questions still need to be improve and there is hope that it will find solutions.

Finally, I think that if state continue increase its supervision, strengthen the construction of teaching staff, management, and improve quality of education system, Tajikistan's postgraduate education system will make a qualitative leap.

\section{REFERENCES}

[1] Higher education in Tajikistan Zarina Nuridinov (NTO Tajikistan). July 2012.

[2] National Strategy For Education Development of the Republic of Tajikistan (2006-2015) Dushanbe, August, 2005.

[3] Factors which affect on the quality of graduate education in our analysis Farhod Rahimov Dushanbe 2011 